\title{
Os gêneros do Primeiro Caderno da Folha de Londrina: a construção de um modelo teórico
}

\author{
Rithielle Aparecida Castellani \\ Universidade Estadual do Norte do Paraná (UENP) \\ Eliana Merlin Deganutti de Barros \\ Universidade Estadual do Norte do Paraná (UENP)
}

\begin{abstract}
Resumo
Este artigo é resultado de pesquisas realizadas no projeto de pesquisa "Gêneros da mídia jornalística como objeto de transposição didática externa”, o qual está inserido no Grupo de Pesquisa GETELIN (UENP/CNPq). Em sua fundamentação teórica o projeto pauta-se nos estudos do Interacionismo Sociodiscursivo (ISD), principalmente em sua vertente didática. A pesquisa teve como principal objetivo elaborar um modelo teórico do Primeiro Caderno da Folha de Londrina. A elaboração do modelo teórico comportou cinco etapas: 1) seleção de um corpus representativo do Primeiro Caderno; 2) estudo bibliográfico da esfera jornalística e dos gêneros do jornal; 3) entrevista com a Folha de Londrina; 4) inventário dos gêneros do Primeiro Caderno; 5) análise e interpretação do Caderno com base nas categorias do ISD e na adaptação feita da categorização de Bonini (2003) para os gêneros do jornal. Para este artigo o objetivo é apresentar os resultados obtidos nas quatro primeiras etapas da pesquisa.
\end{abstract}

Palavras-chave: Primeiro Caderno, Folha de Londrina, modelo teórico, transposição didática.

\begin{abstract}
This article is the result of research in the project "Genres of the journalistic media as an object of external didactic transposition", which is integrated in the GETELIN (UENP/CNPq) research group. In its theoretical grounding, the project is guided by Sociodiscursive Interactionism (ISD) studies, mainly in didactic terms. The main objective of the study was to develop a theoretical model of the First Section of Folha de Londrina. The development of the theoretical model contains five steps: 1) selection of a representative corpus of the first section; 2) bibliographic study of the area of journalism and newspaper genres; 3) interview with Folha de Londrina; 4) list of the First Section genres; 5) analysis and interpretation of the section based on the categories of ISD and on the adaptation of Bonini's (2003) categorization for newspaper genres. For this article the objective is to present the results obtained in the first four steps of the research.

Keywords: First Section, Folha de Londrina, theoretical model, didactic transposition.
\end{abstract}




\section{INTRODUÇÃ̃O}

Neste artigo o objetivo central é apresentar os resultados da elaboração do modelo teórico (BARROS, 2012) do Primeiro Caderno do Jornal Folha de Londrina, o que inclui um estudo bibliográfico e mapeamento do Caderno e de seus gêneros. A finalidade do estudo é auxiliar as pesquisas sobre os gêneros jornalísticos, a fim de que eles possam servir como instrumentos de transposição didática.

Como objeto de análise temos o Jornal Folha de Londrina, mais especificamente seu Primeiro Caderno. O corpus selecionado foram os jornais de Março, Abril e Maio de 2013 (meses de início da pesquisa) de terça feira a sábado, totalizando 66 jornais. A justificativa maior para trabalhar com a Folha de Londrina deve-se ao Programa Social, de cunho educativo que ela desenvolve: o Folha Cidadania. Esse programa tem como intuito diminuir o analfabetismo funcional através do incentivo ao letramento escolar.

Atualmente o ensino da Língua Portuguesa tem se voltado para o trabalho com os gêneros do jornal, entretanto, ainda há uma carência muito grande de pesquisas com essa temática, sobretudo, na área de Estudos da Linguagem (ver BONINI, 2003). Foi pensando nisso que decidimos estudar, a priori, teoricamente, um objeto da esfera jornalística. No caso da nossa pesquisa, a modelização (modelo teórico) não é de um gênero de texto - enunciado relativamente estável que circula nas mais variadas esferas da comunicação (BAKHTIN, 1997) -, mas de um Caderno, que, na nossa pesquisa, estamos considerando um subsuporte do jornal, já que para nós o jornal é um suporte (MARCUSCHI, 2008) e não um hipergênero, como conceitua Bonini (2003). Ou seja, estamos fazendo uma adaptação nos conceitos do Interacionismo Sociodiscursivo (ISD), base teórica de nossa pesquisa. O objetivo é que o modelo teórico construído sirva de suporte não só para processos de transposição didática que serão desenvolvidos no projeto de pesquisa a que nos vinculamos, mas para qualquer um que tenha o Caderno analisado e/ou os gêneros inventariados como instrumentos/ objetos de ensino.

Para a realização da pesquisa, foram estabelecidas cinco etapas: 1) seleção de um corpus representativo do Primeiro Caderno; 2) estudo bibliográfico da esfera jornalística e dos gêneros do jornal; 3) entrevista com a Folha de Londrina; 4) inventário dos gêneros do Primeiro Caderno; 5) análise e interpretação do Caderno com base nas categorias do ISD contexto de produção e plano global - e na adaptação feita da categorização de A. Bonini (2003) para os gêneros do jornal. Para esse artigo, nos detemos nas quatro primeiras etapas. 
Para sistematizar este artigo, foram desenvolvidos os seguintes tópicos: $\mathrm{O}$ Interacionismo Sociodiscursivo: uma corrente da ciência do humano; Contextualizando os gêneros sob o viés da esfera jornalística; Jornal Folha de Londrina; O modelo teórico do Primeiro Caderno da Folha de Londrina; O plano global do Primeiro Caderno.

\section{O INTERACIONISMO SOCIODISCURSIVO: UMA CORRENTE DA CIÊNCIA DO HUMANO}

O Interacionismo Sociodiscursivo (ISD), de acordo com Bronckart (2006), ao mesmo tempo em que aceita os princípios de base do Interacionismo Social (VYGOTSKY, 2008), também expande as ideias deste, uma vez que se centra nas interações humanas mediadas pela linguagem. Porém, mais que uma ciência linguística, o ISD deseja ser uma corrente da ciência do humano, cujo ponto focal está no desvendamento das atividades discursivas. Assim, o ISD propõe um trabalho de investigação com as práticas de linguagens que são efetivadas a partir dos textos/gêneros presentes na sociedade.

[...] as práticas de linguagem situadas (quer dizer, os textos-discursos) são os instrumentos maiores do desenvolvimento humano, não somente sob o ângulo dos conhecimentos e dos saberes, mas, sobretudo, sob o das capacidades de agir e da identidade das pessoas (BRONCKART, 2006, p. 8).

Para a análise desses gêneros que são produzidos diariamente, Bronckart (2003) propõe um "modelo" de análise, o qual organiza-se da seguinte forma: 1) contexto de produção, que se divide em mundo físico e mundo social e subjetivo; 2) arquitetura interna do texto, que se subdivide em infraestrutura textual (plano textual global, tipos de discurso, tipos de sequência ou outras formas de planificação); mecanismos de textualização (conexão, coesão nominal e coesão verbal) e mecanismos enunciativos (vozes e as modalizações). Nessa pesquisa nos detemos ao modelo do plano textual global ${ }^{1}$ do Primeiro Caderno.

O plano textual global, refere-se à composição geral do texto, a partir da estruturação do conteúdo temático; ele é passível de reconhecimento a partir da leitura (BRONCKART, 2003) - é a "fotografia" do gênero. Segundo os pesquisadores de Genebra, ele pode ser esquematizado em forma de um "resumo". A partir do plano textual global pode-se analisar: tipos de discurso, tipos de sequências, os mecanismos de textualização e os mecanismos enunciativos, ou seja, o plano global é o nível mais macro da análise.

\footnotetext{
${ }^{1}$ Neste artigo estamos adaptando o conceito de plano textual global para plano global, pois estamos modelizando um suporte textual e não um gênero de texto.
} 
Em sua vertente didática, o ISD propõe como objeto de ensino os gêneros textuais, e optam por utilizar o conceito de transposição didática que é "o conjunto das transformações que um determinado conjunto de conhecimentos necessariamente sofre, quando temos o objetivo de ensiná-lo, trazendo sempre deslocamentos, rupturas e transformações diversas a esses conhecimentos" (MACHADO; CRISTÓVÃO, 2006, p. 552), ou seja, é transformar um objeto de referência do mundo social/científico em objeto de ensino-aprendizagem. Seguindo essa perspectiva, o ISD elaborou duas ferramentas para o ensino a partir dos gêneros: modelo didático e sequência didática (SD).

O modelo didático baseia-se na análise do gênero, a fim de estabelecer quais de suas dimensões podem ser ensinadas e quais são essenciais para um determinado nível de ensino (MACHADO; CRISTÓVÃO, 2006). Nesse sentido, ele dá suporte para a elaboração de materiais didáticos, os quais podem estar pautados em diferentes metodologias ou procedimentos de ensino.

Ainda pensando na questão da modelização do gênero, Barros (2012) coloca que o modelo do gênero pode ser visto, a priori, apenas teoricamente, ou seja, para construí-lo não é preciso levar em conta as capacidades dos alunos nem o contexto de intervenção didático. $\mathrm{Ou}$ seja, a modelização pode ser realizada de uma forma mais genérica, sem levar em conta a elaboração imediata de um material didático. Assim, Barros (2012) propõe o conceito de modelo teórico do gênero, o qual procura descrever os gêneros, de uma forma teórica, sem pensar, de imediato, no ensino. Evidentemente, esse modelo teórico pode se transformar em um modelo didático, quando for adaptado a um contexto específico de intervenção didática.

É justamente esse conceito de modelo teórico que é explorado pela nossa pesquisa, porém adaptando-o para a análise de um suporte textual: o jornal impresso; uma vez que a modelização foi pensada inicialmente para a descrição de um gênero de texto.

\section{CONTEXTUALIZANDO OS GÊNEROS SOB O VIÉS DA ESFERA JORNALÍSTICA}

O jornalismo é uma importante esfera comunicativa e atualmente os gêneros dessa esfera têm sido abordados por vários pesquisadores, tanto na área jornalística como no campo dos estudos da linguagem. Entretanto, segundo Bonini (2003), ainda há um desconhecimento desse conceito, mesmo na área da comunicação.

Embora o conceito de gêneros jornalísticos não seja totalmente transparente nos estudos do campo da comunicação, para investigarmos os gêneros do jornal nos apoiamos nas 
pesquisas dessa área, pois é a partir dela que as práticas discursivas do jornal se realizam, ou seja, tomamos como parâmetros o ponto de vista dos sujeitos envolvidos nessa esfera social.

Segundo Medina (2001, p. 50), os gêneros jornalísticos "servem para orientar os leitores a lerem os jornais, permitindo-os identificar as formas e os conteúdos dos mesmos". Ou seja, mesmo que esse leitor não consiga nomear os gêneros presentes no jornal, ele consegue compreender seu funcionamento.

No estudo do jornalismo, um dos primeiros autores que se preocupou com a classificação dos gêneros foi Luiz Beltrão (1969,1976,1980). Segundo Melo (1985), a perspectiva adotada por Beltrão é estritamente funcional. Ele realiza uma separação dos gêneros de acordo com as funções que eles desempenham, a partir de três polos: "informar, explicar e orientar”. Posteriormente, Melo (1985), baseando-se em Luiz Beltrão, classifica os gêneros em duas categorias: jornalismo informativo e jornalismo opinativo. O primeiro é caracterizado por gêneros que estão necessariamente ligados à "eclosão" e evolução de determinado fato e também à associação que os jornalistas estabelecem com os personagens dos acontecimentos. O segundo refere-se a gêneros com caráter avaliativo, os quais "assumem duas feições: autoria (quem emite a opinião) e angulagem (perspectiva temporal ou espacial que dá sentido à opinião)" (MELO, 1985, p. 48).

A preocupação inicial de Melo (1985) foi “categorizar" os gêneros do jornal, a partir da função que realizam. Ao contrário dele, em nossa pesquisa, nós não diferenciaremos jornalismo informativo de opinativo, pois acreditamos ser essa uma questão muito relativa na discursividade atual do jornal, uma vez que há uma tendência natural de imbricamento entre a informação e a opinião nos gêneros do jornal, tirando a "pureza" discursiva que tradicionalmente sempre os caracterizaram (exemplo são as notícias/reportagens em que aparecem opiniões do jornalista, implícita ou explicitamente). Ou seja, não buscamos classificar os gêneros a partir dessas categorias, mas sim compreender sua prática comunicativa no funcionamento do jornal, tomando como referência tanto o teor informativo como o opinativo.

Um pesquisador da área de estudos da linguagem que tem contribuído para uma compreensão discursiva dos gêneros jornalísticos é Adair Bonini (2003). Por isso, nos atemos mais às suas pesquisas, já que elas estão mais próximas dos nossos objetivos.

Bonini (2003) fez um levantamento dos gêneros jornalísticos a partir da literatura da área de comunicação brasileira. Com isso, elaborou uma primeira divisão dos gêneros, tomando, para isso, sua funcionalidade dentro do jornal: 
Quadro 1 - Categorias da funcionalidade do jornal, de Adair Bonini

\begin{tabular}{|l|l|}
\hline $\begin{array}{l}\text { Gêneros da atividade } \\
\text { jornalística }\end{array}$ & $\begin{array}{l}\text { São aqueles que estão presentes no ambiente de produção do } \\
\text { jornal. }\end{array}$ \\
\hline Gêneros do jornal & São aqueles que ocorrem no jornal. \\
\hline Gêneros centrais no jornal & $\begin{array}{l}\text { São aqueles que estão diretamente relacionados à organização e aos } \\
\text { principais objetivos sociais/comunicacionais do jornal (relatar, } \\
\text { prever e analisar acontecimentos). }\end{array}$ \\
\hline Gêneros centrais presos & São aqueles que estruturam o jornal. \\
\hline Gêneros centrais livres & São aqueles que fazem o jornal funcionar. \\
\hline $\begin{array}{l}\text { Gêneros centrais livres } \\
\text { autônomos }\end{array}$ & $\begin{array}{l}\text { Embora também possam se mesclar, são os que mais comumente } \\
\text { acontecem como unidades textuais independentes ou } \\
\text { predominantes em um bloco de textos. }\end{array}$ \\
\hline $\begin{array}{l}\text { Gêneros centrais livres } \\
\text { conjugados }\end{array}$ & $\begin{array}{l}\text { Ocorrem, em geral, como apêndice dos gêneros autônomos, } \\
\text { principalmente da reportagem. }\end{array}$ \\
\hline Gêneros periféricos & $\begin{array}{l}\text { Estão relacionados a propósitos sociais/comunicacionais que } \\
\text { incidem sobre o jornal, como os de promover produtos e pessoas, } \\
\text { divertir, educar, cumprir normas legais, contratar pessoal, etc. }\end{array}$ \\
\hline
\end{tabular}

Fonte: Bonini (2003, p 221)

Essa divisão estabelecida por Bonini (2003) parte da funcionalidade do gênero dentro do contexto jornalístico, porque "estas divisões não são categorias que explicam o gênero, mas o processo social e de linguagem em que ele está envolvido. Tenta-se, desse modo, descrever o gênero pelo modo como ele funciona no jornal.” (BONINI, 2003, p. 222).

A partir dessa divisão por categorias funcionais dos gêneros do jornal, Bonini (2003) realiza um mapeamento desses gêneros, apoiando-se tanto no levantamento das pesquisas da área do jornalismo, como de manuais de estilo jornalísticos e dicionários de comunicação. Esse inventário, embora bastante relevante para os estudos da área, ainda é feito de forma teórica, sem o apoio de um corpus real contemporâneo. No nosso caso, o objetivo é inventariar os gêneros do jornal Folha de Londrina, para fins de transposição didática, por isso, na seção seguinte, ao realizarmos o mapeamento do Primeiro Caderno, utilizamos tanto a classificação de Bonini (2003), como de autores do jornalismo, mas sempre voltados para a funcionalidade discursiva que nosso corpus nos apresenta.

Bonini (2003), diferentemente do ISD e de diversos pesquisadores da área, não trata o jornal como um suporte textual, mas como um hipergênero. Bonini (2001) afirma que

Embora na literatura sobre gêneros textuais o jornal seja caracterizado basicamente como um veículo, [há] motivos para considerá-lo um gênero que abriga outros (ou seja, um hipergênero), porque preenche quesitos como propósitos comunicativos próprios, organização textual característica [...] e produtores e receptores definidos. (apud BONINI, 2008, p. 35)

Ou seja, Bonini (2005) desconsidera o conceito de "suporte" em detrimento de "hipergênero". Entretanto, nós consideramos o jornal como um suporte, um "locus físico ou 
virtual com formato específico que serve de base ou ambiente de fixação do gênero materializado como texto" (MARCUSCHI, 2003, p. 11). Assim, consideramos o jornal um veículo de comunicação que comporta vários gêneros que resultam de integração de diferentes esferas sociais - do entretenimento, artística, política, etc. Também adotamos o termo subsuporte, ou seja, dentro do suporte maior que é o jornal, temos outros subsuportes que fixam determinados gêneros no jornal. Um exemplo claro é a coluna, pois como Bonini (2003), não consideramos a coluna como um gênero, porém, diferentemente do autor, a classificamos como um subsuporte (um espaço físico e fixo dentro do jornal) que pode receber diferentes gêneros. Outros subsuportes são as seções e os Cadernos do jornal, que além de servirem como organizadores textuais e temáticos, agrupam diferentes gêneros, que podem ocorrer periodicamente ou não.

Ainda pensando no conceito de suporte, concebemos que o jornal é um veículo no qual estão presentes diferentes esferas da sociedade, não apenas a esfera jornalística. Dessa forma, há uma hibridização nos gêneros do jornal, ou seja, uma mistura dos gêneros, na qual não ocorrem apenas gêneros da esfera jornalística, mas também gêneros da esfera do entretenimento, política, econômica, cultural.

Portanto, em nossa pesquisa, comungamos com a divisão realizada por Bonini (2003) a partir da função do gênero dentro da atividade jornalística, entretanto, nós não adotamos na íntegra a rede conceitual criada por ele para o estudo dos gêneros do jornal/jornalísticos. Nós a simplificamos, desconsiderando as categorias de gêneros livres e presos, pois estamos focados na transposição didática, conforme descrito abaixo. Essa rede conceitual será utilizada para o mapeamento do Primeiro Caderno da Folha de Londrina.

\section{JORNAL FOLHA DE LONDRINA}

Em nossa pesquisa, utilizamos como objeto de análise o Jornal Folha de Londrina, mais especificamente o seu Primeiro Caderno. A Folha de Londrina é um jornal publicado na cidade de Londrina, que circula em 300 municípios do Estado do Paraná, além de estados como Mato Grosso e do Sul de São Paulo, atendendo, assim, uma média de 120 mil leitores por dia.

A Folha de Londrina é composta por vários cadernos, que variam conforme o dia. Aos domingos ela traz seis cadernos: Primeiro Caderno, Folha Esporte, Folha 2, Folha Gente,

\footnotetext{
${ }^{2}$ Informações retiradas do site da Folha de Londrina: www.folhaweb.com.br. Acesso em: 09/07/2014 e da entrevista com editores da Folha de Londrina realizada em Novembro de 2011.
} 
Carro \& Cia e Classificados. Na segunda-feira, ele apresenta apenas dois cadernos: Primeiro Caderno e Folha Lance. Às terças-feiras o jornal publica: Primeiro Caderno, Folha Economia, Folha Esporte, Folha Cidades, Folha 2 e Classificados. Na quarta-feira temos: Primeiro Caderno, Folha Economia, Folha Esporte, Folha Cidades, Folha 2, Folha Casa \& Conforto e Classificados. Na quinta-feira são publicados: Primeiro Caderno, Folha Economia, Folha Esporte, Folha Cidades, Folha 2 e Classificados. De sexta-feira, o jornal apresenta: Primeiro Caderno, Folha Economia, Folha Esporte, Folha Cidades, Folha 2 e Classificados. E por fim, no sábado temos: Primeiro Caderno, Folha Economia, Folha Cidades, Folha 2, Classificados e Folha Rural.

Para contextualizarmos o funcionamento do jornal, realizamos uma entrevista com a Folha de Londrina, mais especificamente com uma editora do Caderno Folha 2, responsável pelo Programa Folha Cidadania. Foi justamente esse programa que nos motivou a trabalhar com esse jornal, pois, como já mencionado, o nosso foco principal é o ensino da Língua Portuguesa, e o Folha Cidadania, segundo o jornal, é um programa de combate ao analfabetismo funcional, voltado para as crianças, com foco no incentivo à leitura, atendendo escolas das redes pública e particular de ensino de Londrina e região. O projeto está presente no jornal desde 1984. No início seu objetivo era somente incentivar a leitura e o senso crítico nas crianças, entretanto, hoje, com todas as mudanças ocorridas, o programa visa diminuir o analfabetismo funcional.

O projeto atende atualmente cerca de 115 escolas, situadas nas cidades de Londrina, Cambé, Jataizinho, Alvorada do Sul, Bela Vista do Paraíso, Ibiporã e Rolândia. A Folha Cidadania apresenta-se concretamente no jornal às terças-feiras, por meio de duas estratégias: 1) uma matéria jornalística já veiculada recentemente, em formato de box, em cada Caderno do jornal - o texto é selecionado pelas editorias e sofre um tratamento didático: algumas expressões são destacadas para serem explicadas, aprofundadas, conceituadas; 2) veiculação, nas páginas centrais da Folha 2, de uma reportagem direcionada especificamente à Folha Cidadania, sobre ações voltadas a experiências pedagógicas de escolas da região (sobretudo, escolas parceiras do Programa Folha Cidadania).

\section{O MODELO TEÓRICO DO PRIMEIRO CADERNO DA FOLHA DE LONDRINA}

Nesta pesquisa, como já indicado na introdução do artigo, nosso objetivo é elaborar um modelo teórico (BARROS, 2012) da Primeiro Caderno da Folha de Londrina, para que ele possa servir como instrumento mediador de projetos escolares centrados na transposição 
didática de gêneros do jornal - sobretudo, projetos que trabalhem com a Folha de Londrina como ferramenta didática. Para tanto, buscamos fazer um inventário dos gêneros que compõem esse Caderno, a fim de explicitá-los, descrevendo e problematizando o seu funcionamento contextual e discursivo. Nesse sentido, primeiramente, fizemos uma vasta pesquisa bibliográfica sobre a esfera jornalística e os gêneros por ela veiculados, para servir de suporte à etapa do mapeamento dos gêneros, a qual é fundamentada na categoria de plano global. Apresentamos, primeiramente, a análise do plano global do Primeiro Caderno.

\section{O plano global do Primeiro Caderno}

O Primeiro Caderno é o principal do jornal Folha de Londrina, sendo o único fixo no jornal, ocorrendo todos os dias da semana. É um dos maiores cadernos, podendo variar de 8 a 14 páginas, conforme o dia. Ele possui o maior número de seções do jornal, que podem variar nos dias de publicação, mas que são próprias apenas desse Caderno: Opinião, Política, Geral e Mundo. Entretanto, aos domingos e segundas-feiras, o Primeiro Caderno aborda seções que não são recorrentes, mas são especiais desses dois dias, pois só ocorrem neles. No domingo, ele traz as seções: Entrevista, Economia e a Reportagem. E na segunda-feira, é publicado apenas o Primeiro Caderno e a Folha Lance, portanto, além de apresentar suas seções fixas, o Primeiro Caderno também aborda outros cadernos que se tornam seções: Esporte, Economia e Folha 2. Assim, além de suas seções, o Primeiro Caderno, eventualmente, comporta seções com temáticas próprias de outros Cadernos do jornal, que, naquele dia, não são veiculados. Isso pode ocorrer com o Caderno Esporte, Economia e Folha 2.

Para realização da nossa pesquisa fizemos um levantamento dos gêneros do Primeiro Caderno da Folha de Londrina, tomando como corpus de análise exemplares dos meses de Março, Abril e Maio de 2013, de terça-feira a sábado (optamos por não usar os jornais de domingo e segunda pelo fato de nesses dias o Primeiro Caderno incorporar outros, em forma de seções), somando 66 jornais, a fim de conhecermos os gêneros do Caderno e seu funcionamento.

Para esse levantamento buscamos respaldo de pesquisas bibliográficas sobre os gêneros jornalísticos: estudiosos da área da Comunicação e dos estudos da Linguagem, entre eles, Melo (1985), Faria e Zanchetta Jr. (2007) e Bonini (2003); e também do nosso conhecimento como leitoras de jornais. Nessa investigação, foram inventariados os seguintes gêneros do jornal: Chamada de capa; carta do leitor; artigo de opinião; charge; editorial; notícia; reportagem; foto/legenda; infográfico; nota (coluna "Informe Folha"); nota 
comentada (coluna "Cláudio Humberto" e "Luiz Geraldo Mazza"); Placar; Agenda esportiva; ensaio (coluna "Dora Kramer"). Ao total são quatorze gêneros ${ }^{3}$ levantados no primeiro caderno. Dessa forma, a disposição desses gêneros no Primeiro Caderno é a seguinte:

A chamada de capa sempre ocorre no Primeiro Caderno, vem apresentada logo no início, na capa. Ela apresenta um título, que normalmente é uma palavra, ou uma frase nominal, e um pequeno texto sobre a matéria que estará nas seções do jornal, juntamente com a página ou o caderno correspondente. Segundo Faria e Zanchetta Jr. (2007, p. 44), "a chamada é um breve texto, somado a outros procedimentos de informação como fotos e gráficos, colocados na primeira página da edição [...] antecipando elementos da notícia contida no interior do jornal". O que denominamos chamada é um gênero que pode trazer: antitítulo, título, texto-síntese da matéria jornalística, foto, figura, referência à página ou seção/Caderno do jornal. Esses elementos (ou parte deles) são conjugados, dependendo da ênfase que o jornal quer dar à matéria jornalística - isso pode ser feito utilizando-se de vários recursos paralinguísticos, como tamanho, formato e cor da fonte da escrita, colorido da imagem, destaque de cor no fundo da chamada, etc.

Os gêneros editorial, carta do leitor, artigo de opinião e charge estão dispostos na primeira seção do Primeiro Caderno, a Opinião, que aparece na contracapa do jornal. Essa seção é fixa no jornal, assim como esses gêneros. O editorial é um gênero de responsabilidade da Folha de Londrina. Ele discorre sobre assuntos de certa forma relevantes para os leitores, deixando traços de opinião no texto. Apesar de ser um gênero com teor opinativo, o editorial da Folha também possui características analíticas, descritivas e explicativas, que em alguns casos, acabam se sobressaindo à própria opinião. Para a escrita do editorial, segundo o Jornal Folha de Londrina, há sempre um rodízio entre os editores do jornal, ou seja, cada editorial é escrito por um editor da Folha. Segundo Melo (1985, p. 79), o editorial "é um gênero jornalístico que expressa a opinião oficial da empresa diante dos fatos de maior repercussão no momento", dessa forma, o editorial é um gênero opinativo, que preserva os fatos, expõe a opinião de forma mais reservada, para não denegrir a imagem do jornal.

A carta do leitor também é um gênero com características opinativas. Essas cartas são escritas e enviadas por leitores da Folha de Londrina, a fim de que eles possam expressar sua opinião sobre alguma notícia/reportagem ou qualquer outra matéria que tenha sido publicada no jornal. Nas cartas, a opinião e as críticas ficam bem explícitas. O leitor escreve abertamente, deixando clara sua opinião sobre determinado assunto e defendendo seu ponto

\footnotetext{
${ }^{3}$ Consideramos, no Primeiro Caderno, apenas os gêneros de maior relevância para nossa pesquisa. Portanto, esse número não corresponde ao total de gêneros do caderno, e, sim, aos que nós inventariamos.
} 
de vista a partir de seus argumentos. Segundo a Folha, há uma seleção entre as cartas e aquelas que serão publicadas passam por uma editoração. O revisor, responsável pelas cartas, deve editá-las para que elas estejam adequadas ao espaçamento do jornal, pois há um número máximo de caracteres, e também para que os textos sejam claros, olhando questões ortográficas, de concordância e vocabulário, mas sempre preservando a ideia do leitor, a fim de que ela possa ser bem interpretada. Para Medina (2001, p. 54) "a carta é um recurso em que o leitor pode expressar seus pontos de vista e opiniões".

O artigo, também um gênero opinativo, é um texto mais longo, enviado por leitores do jornal e é sempre assinado. Os artigos da Folha também possuem um número máximo de caracteres, o qual o articulista deve respeitar. Segundo Melo (1985, p. 92) "trata-se de uma matéria jornalística onde alguém (jornalista ou não) desenvolve uma ideia e apresenta sua opinião".

Por fim, a charge, que é um gênero opinativo com um teor mais crítico. Ela é produzida a partir de assuntos atuais, assim, a charge é um gênero com características momentâneas, ou seja, pode ser que em outro momento não consigamos compreender a mensagem que esse gênero quer passar, por não ser um assunto atual. As charges da Folha de Londrina normalmente tratam de assuntos políticos, e são escritas sempre pelo mesmo chargista. Segundo Faria e Zanchetta Jr. (2007, p. 128), a charge "é um cartum de crítica a um acontecimento, geralmente de natureza política". Assim, esses gêneros que compõem a seção opinião atraem leitores mais críticos, que buscam saber opiniões de outros cidadãos, sejam elas contrárias às suas ou não. É uma seção que não deixa de informar, entretanto nela prevalece o teor opinativo dos gêneros.

Os gêneros "cabeças" do jornal, notícia e reportagem, estão presentes em quase todas as seções (Política, Mundo, Esporte, Geral), pois são seções que de forma geral trazem os principais conteúdos, também o coração do jornal: a informação. Para diferenciarmos esses dois gêneros tivemos um pouco de dificuldade, pois eles são muito semelhantes. Entretanto, como não objetivamos descrever sistematicamente as características dos gêneros e, além disso, estamos focados na transposição desses gêneros para o ensino, para nós essa distinção não precisa ser tão "radical". Dessa forma, não nos preocupamos em distingui-los cautelosamente, pois "nem mesmo para os jornalistas parece fácil a tarefa de defini-la [a distinção entre notícia e reportagem] de modo mais satisfatório" (FRANCESCHINI, 2004, p.148). Para conseguirmos distinguir os dois gêneros no momento do nosso mapeamento, nós nos ativemos ao lide (FARIA; ZANCHETA, 2007) e também à forma como o assunto é abordado no texto. O lide conhecido como "cabeça", está presente na abertura da notícia ou 
reportagem (FARIA; ZANCHETTA, 2007), é ele quem irá encaminhar o texto, organizando as informações. "O lide integral é o mais comum na imprensa brasileira. Está concentrado geralmente nos dois primeiros parágrafos e responde a perguntas básicas (QUEM- O QUEQUANDO- ONDE- COMO- POR QUE)" (FARIA; ZANCHETA, 2007, p. 29). O lide é utilizado como um instrumento para reconhecer esses dois gêneros e diferenciá-los, pois por mais que os dois tenham o lide, ambos os abordam de forma diferente.

A notícia é um gênero mais sintético, responde às questões do lide (ou não, pois não necessariamente elas precisam estar todas no texto) de forma mais objetiva, trazendo alguns detalhes, mas se limitando para não fugir das suas características. As notícias na Folha de Londrina, em sua estrutura, seguem o lide e também apresentam outras características do texto noticioso, como: objetividade, atualidade, extensão, abordagem do assunto e veracidade. Elas trazem apenas o essencial do fato sobre o qual estão informando, sem se prolongar muito. A notícia também pode trazer a voz de algum personagem do caso noticiado, para poder dar concretude, porém, não se prolonga muito, nem detalha precisamente o assunto, pois isso não é uma característica sua. Seu título segue a ordem sujeito+verbo+complemento, sempre apresentado no tempo verbal do presente.

Na Folha, a maioria das notícias vem acompanhada pela foto/legenda (gênero conjugado), que complementa a informação transmitida no texto. Ela também pode vir acompanhada pelo infográfico para auxiliar na informação, entretanto, isso não é tão comum, visto que a notícia tende a ser mais rápida e aborda os fatos de forma mais objetiva.

A reportagem, também apresenta o lide, mas com maior abrangência. Ela dá maior destaque aos fatos, o texto apresenta mais vozes, entrevistados, personagens, testemunhas. Assim, consideramos que a reportagem, além de responder a outras questões do lide, apresenta ênfase maior no COMO e no PORQUE, visto que são essas duas questões que trazem o como determinado fato aconteceu, e o porquê aconteceu, dessa forma, a reportagem revela todas as características que são limitadas pela notícia. Pensando na reportagem, e nas diferenças que encontramos entre algumas publicadas na Folha, nós a dividimos em duas categorias: noticiosa e temática. A noticiosa caracteriza-se como um texto mais longo, que aborda determinado fato atual, algo que esteja repercutindo na sociedade. Ela analisa os fatos, traz diferentes versões, entrevistas com envolvidos no assunto, testemunhas, enfim, busca completar todas as informações para os leitores que as notícias não suprem. Ela pode vir acompanhada pela foto/legenda ou pelo infográfico, ou pelos dois juntos, sempre buscando passar o máximo de informação possível, fazendo com que o leitor se inteire totalmente de determinado assunto. Seus títulos também seguem a ordem sujeito+verbo+complemento, e 
também são escritos no tempo Presente. A reportagem temática segue as mesmas características da noticiosa quanto ao título, tempo verbal, abordagem detalhada do assunto, presença de foto/legenda e infográfico, porém, os assuntos sobre os quais ela discorre não partem de uma notícia, mas, sim, de temas de interesse comum, como por exemplo: doenças cardíacas, os malefícios do cigarro, o problema da dengue, etc. Nesse caso, os jornalistas buscam informações com pessoas ligadas ao assunto, como um médico, Secretário de Saúde. As reportagens temáticas da Folha são mais comuns em cadernos específicos como Folha 2, Economia, Folha Cidades, mas elas também acontecem no Primeiro Caderno, porém com menor frequência. Assim "a reportagem trata de assuntos, e não necessariamente de fatos novos. Seu objetivo é contar uma história verdadeira, expor uma situação ou interpretar fatos." (FRANCESCHINI, p. 150).

A foto/legenda e infográfico são gêneros conjugados, pois sempre aparecem junto com outro gênero: geralmente uma notícia ou reportagem. Também ocorrem nas seções Política, Geral e Mundo. A foto/legenda, como o nome diz, é uma foto que ilustra o assunto tratado na notícia ou reportagem, ela vem apresentada juntamente com a legenda que explica essa foto, por isso consideramos um único gênero, pois eles só funcionam juntos, ou seja, se colocássemos somente uma legenda na notícia, esta não faria sentido, assim como se colocássemos apenas uma foto, a informação desta não seria completa. $\mathrm{O}$ infográfico tem o intuito de ilustrar, complementar determinada notícia/reportagem, para auxiliar na informação que será passada para o leitor. Segundo Faria e Zanchetta (2007, p. 83), “os jornais impressos desenvolvem soluções híbridas entre texto e imagem”. Entretanto, ele não é tão comum no Primeiro Caderno, mas, ainda assim há ocorrência. O infográfico apresenta sempre um gráfico comparativo ou explicativo, com apresentação de números, cálculos, diferenças, etc., para complementar a matéria a qual acompanha.

Os gêneros placar e agenda esportiva ocorrem no Primeiro Caderno apenas quando este traz a seção Esporte, pois são gêneros específicos desta seção. O placar é realmente um placar esportivo. Ele traz as colocações dos times de acordo com o campeonato (paranaense, paulista, espanhol, etc.), e também o placar de jogos que já aconteceram. Não encontramos, a priori, nenhuma nomenclatura característica para esse gênero, por isso aderimos ao nome apresentado no jornal, e também por fazer parte do senso comum dos leitores do caderno Esporte. A agenda esportiva, diferentemente do placar, não é apresentada com esse nome no jornal, nós a classificamos assim devido às suas características, pois se trata de uma agenda para os leitores desse Caderno, chamando a atenção para os próximos jogos. A agenda vem 
em pequenas tabelas distribuídas no caderno, ela traz o local onde acontecerão os jogos, as equipes participantes, assim como a formação do time (jogador, técnico, árbitro).

Já os gêneros nota, nota comentada e ensaio aparecem conjugados a uma coluna espaço fixo dentro do jornal.

Para classificar os gêneros presentes nas Colunas encontramos muitas dificuldades. Primeiramente, tivemos que decidir se consideraríamos coluna como gênero ou não, uma vez que há pesquisadores que a tratam como gênero (ver FONTANA; PAVIANI; PRESSANTO, 2009; BARROS, 2002) e outros que a tratam como um espaço fixo dentro do jornal/revista (ver BONINI, 2003). Decidimos considerar a coluna como um espaço fixo do jornal que pode abarcar vários gêneros. Isso ficou claro na nossa pesquisa, uma vez que verificamos que cada coluna se comporta discursivamente de forma singular, assim, não teria como considerá-la um gênero. Vale ressaltar que existem colunas assinadas ou não assinadas e, algumas vezes, são denominadas de "painéis" - talvez pelo fato de esses, na maioria das vezes, se apresentarem horizontalmente no jornal (ver JÓIA, 2014).

Outra dificuldade para classificar os gêneros dessas colunas é que tanto a nota como o ensaio não são nomenclaturas que perpassam o senso comum, além de não terem definições consolidadas tanto na área do jornalismo, como dos Estudos da Linguagem. O gênero que nós nomeamos nota é apresentado na coluna do jornal Folha de Londrina como "Informe Folha". Para nós, a nota é um resumo de determinado fato, ela traz o assunto de forma bem sintetizada, abordando apenas o essencial. Não consideramos nota, aqui, como um pronunciamento da empresa, mas, sim, como o "resumo" de uma notícia. Outra característica da nota é seu título, que diferentemente da notícia ou reportagem não é uma frase com SUJEITO+VERBO+COMPLEMENTO, mas sim uma frase nominal, ou apenas uma palavra com teor adjetivo, ou uma palavra que resuma todo o assunto que é noticiado. A nota comentada, de início foi tomada como um comentário, entretanto, depois de analisá-la e estudarmos sobre o gênero comentário notamos que há pequenas diferenças. O comentário, segundo Medina (2001, p. 54), é um "pequeno artigo interpretativo de um fato". Assim, o comentário busca comentar, mais do que informar, ou seja, a opinião do comentarista sobressai a informação. Nas colunas assinadas "Cláudio Humbero" e "Luiz Geraldo Mazza", ocorre, sim, o comentário; os colunistas se posicionam ou no texto, ou no próprio título, mas, também há a notícia, que caminha lado a lado com esse comentário, com a opinião do colunista. Assim, ocorre um imbricamento entre os dois, ora a notícia sobressai, ora o comentário, por isso não consideramos os gêneros dessa coluna apenas como comentário. A nota comentada é curta, segue um padrão, o estilo do colunista. Seu título, na maioria das 
vezes, é uma frase nominal, ou apenas uma palavra de impacto, que resuma a opinião do escritor ou com valor metafórico. As notas comentadas da coluna "Cláudio Humberto" às vezes seguem apenas uma notícia (que vem apresentada logo no início, como base para o restante), ou trazem um grande número de notas sobre ela, que abordam outras peculiaridades acerca do fato. Também há uma nota fixa, "Poder sem pudor", nela há a abordagem de um fato como se fosse o diálogo de uma pequena "historinha", ironizando o assunto. Na coluna "Luiz Geraldo Mazza", as notas comentadas também trazem títulos de apenas uma palavra impactante ou uma frase nominal, cada uma parte de um fato diferente, todas com opinião, posição do colunista.

Por fim temos o ensaio, presente na coluna "Dora Kramer". O que chamamos de ensaio é um texto discursivo, com teor opinativo, mas que não defende um posicionamento, uma tese, apenas discorre sobre determinado assunto mostrando a opinião de quem escreve, mas com menos criticidade do que em um artigo de opinião, por exemplo. Os ensaios nessa coluna são sempre sobre temas atuais e que possuem certa relevância, muitas vezes a coluna traz até dois textos, cada um partindo de um assunto.

Para nos aprofundarmos na funcionalidade dos gêneros do Primeiro caderno, realizamos uma pesquisa quantitativa da ocorrência desses gêneros durante o período compreendido pelo nosso corpus, a qual é apresentada a seguir.

Quadro 2 - Representatividade dos gêneros no Primeiro Caderno

\begin{tabular}{|l|l|l|l|}
\hline Inventário dos gêneros do Primeiro Caderno: meses de Março, Abril e Maio de 2013 \\
\hline Gêneros do jornal & $\begin{array}{l}\text { Conceitos adaptados de } \\
\text { Bonini (2003) }\end{array}$ & Quantidade & $\%$ \\
\hline Chamada & Central & 515 & $11,1 \%$ \\
\hline Carta do Leitor & Central/autônomo & 311 & $6,7 \%$ \\
\hline Artigo & Central/autônomo & 76 & $1,6 \%$ \\
\hline Editorial & Central/autônomo & 66 & $1,4 \%$ \\
\hline Charge & Central/autônomo & 66 & $1,4 \%$ \\
\hline Notícia & Central/autônomo & 715 & $15,4 \%$ \\
\hline Reportagem & Central/autônomo & 541 & $11,7 \%$ \\
\hline Foto/Legenda & Conjugado & 455 & $9,8 \%$ \\
\hline Nota comentada/Cláudio Humberto & Conjugado & 997 & $21,5 \%$ \\
\hline Nota comentada/Luiz Geraldo Mazza & Conjugado & 322 & $6,9 \%$ \\
\hline Nota/Informe Folha & Conjugado & 563 & $1,3 \%$ \\
\hline Ensaio/Dora Kramer & Conjugado & 64 & $12,1 \%$ \\
\hline Infográfico & Conjugado & 47 & $1,01 \%$ \\
\hline Placar & Autônomo & 14 & $0,3 \%$ \\
\hline Agenda esportiva & Autônomo & 25 & $0,5 \%$ \\
\hline Box Folha cidadania (reportagem) & & 33 & $0,4 \%$ \\
\hline TOTAL & & 4807 & $100 \%$ \\
\hline
\end{tabular}


Vale ressaltar que o percentual dos gêneros é obtido a partir da frequência dos textos relativos aos gêneros do Caderno, ou seja, não nos atemos à disposição desses gêneros em relação ao espaço que eles ocupam no jornal, pois não buscamos saber qual a percentagem em espaço físico esses gêneros ocupam, mas sim, sua frequência no Primeiro Caderno.

Os gêneros chamada e carta do leitor, assim como as colunas Cláudio Humberto, Luiz Geraldo Mazza, Dora Kramer, Informe Folha, apresentam grande incidência, pois todos os textos foram contados, não apenas a presença do gênero no Primeiro Caderno. O artigo, editorial e a charge apresentam números menores, porque têm uma presença de textos mais estrita. $\mathrm{O}$ editorial sempre traz um único texto. $\mathrm{O}$ artigo, na maioria das vezes, é apenas um texto, ocasionalmente dois, e a charge é sempre uma. No caso da notícia e da reportagem o número mostra que há a incidência maior de notícia no Primeiro Caderno, entretanto, como já abordamos, não calculamos esses valores por área publicada e, sim, por contagem dos textos. A baixa incidência dos gêneros Placar e Agenda Esportiva ocorre porque estes não são comuns do Primeiro Caderno, eles só acontecem quando a Folha Esporte aparece como uma seção do Primeiro Caderno. O infográfico também tem é pouco frequente, pois é mais comum em cadernos como o Economia e Cidades. E por fim, as reportagens do Folha Cidadania, que aparecem em baixo número, pois só são publicadas às terças-feiras, com um exemplar em cada seção do Primeiro Caderno.

Para sintetizar nossas análises, organizamos um esquema do plano global do Primeiro Caderno: 
Quadro 3 - Síntese do plano global do Primeiro Caderno

\begin{tabular}{|c|c|c|c|c|}
\hline Terça-feira & Quarta-feira & Quinta-feira & Sexta-feira & Sábado \\
\hline Seções e gêneros & Seções e gêneros & Seções e gêneros & Seções e gêneros & Seções e gêneros \\
\hline $\begin{array}{l}\text { Opinião: editorial, } \\
\text { artigo de opinião, } \\
\text { carta do leitor e } \\
\text { charge. }\end{array}$ & $\begin{array}{l}\text { Opinião: editorial, } \\
\text { artigo de opinião, } \\
\text { carta do leitor e } \\
\text { charge. }\end{array}$ & $\begin{array}{l}\text { Opinião: editorial, } \\
\text { artigo de opinião, } \\
\text { carta do leitor e } \\
\text { charge. }\end{array}$ & $\begin{array}{l}\text { Opinião: editorial, } \\
\text { artigo de opinião, } \\
\text { carta do leitor e } \\
\text { charge. }\end{array}$ & $\begin{array}{l}\text { Opinião: editorial, } \\
\text { artigo de opinião, } \\
\text { carta do leitor e } \\
\text { charge. }\end{array}$ \\
\hline $\begin{array}{l}\text { Politica: noticia, } \\
\text { reportagem, foto- } \\
\text { legenda, } \\
\text { *infográfico. }\end{array}$ & $\begin{array}{l}\text { Politica: noticia, } \\
\text { reportagem, foto- } \\
\text { legenda, } \\
\text { *infográfico. }\end{array}$ & $\begin{array}{l}\text { Política: noticia, } \\
\text { reportagem, foto- } \\
\text { legenda, } \\
\text { *infográfico. }\end{array}$ & $\begin{array}{l}\text { Política: noticia, } \\
\text { reportagem, foto- } \\
\text { legenda, } \\
\text { *infográfico. }\end{array}$ & $\begin{array}{l}\text { Política: noticia, } \\
\text { reportagem, foto- } \\
\text { legenda, } \\
\text { *infográfico. }\end{array}$ \\
\hline $\begin{array}{l}\text { Geral: notícia, } \\
\text { reportagem, foto- } \\
\text { legenda e } \\
\text { *infográfico. }\end{array}$ & $\begin{array}{l}\text { Geral: notícia, } \\
\text { reportagem, foto- } \\
\text { legenda e } \\
\text { *infográfico. }\end{array}$ & $\begin{array}{l}\text { Geral: notícia, } \\
\text { reportagem, foto- } \\
\text { legenda e } \\
\text { *infográfico. }\end{array}$ & $\begin{array}{l}\text { Geral: notícia, } \\
\text { reportagem, foto- } \\
\text { legenda e } \\
\text { *infográfico. }\end{array}$ & $\begin{array}{l}\text { Geral: notícia, } \\
\text { reportagem, foto- } \\
\text { legenda e } \\
\text { *infográfico. }\end{array}$ \\
\hline $\begin{array}{l}\text { Mundo: notícia, } \\
\text { reportagem, foto- } \\
\text { legenda, } \\
\text { *infográfico. }\end{array}$ & $\begin{array}{l}\text { Mundo: notícia, } \\
\text { reportagem, foto- } \\
\text { legenda, } \\
\text { *infográfico. }\end{array}$ & $\begin{array}{l}\text { Mundo: notícia, } \\
\text { reportagem, foto- } \\
\text { legenda, } \\
\text { *infográfico. }\end{array}$ & $\begin{array}{l}\text { Mundo: notícia, } \\
\text { reportagem, foto- } \\
\text { legenda, } \\
\text { *infográfico. }\end{array}$ & $\begin{array}{l}\text { Mundo: notícia, } \\
\text { reportagem, foto- } \\
\text { legenda, } \\
\text { *infográfico. }\end{array}$ \\
\hline $\begin{array}{l}\text { Boxes da Folha } \\
\text { Cidadania: } \\
\text { reportagem. }\end{array}$ & & $\begin{array}{l}\text { Esporte*: notícia, } \\
\text { reportagem, placar, } \\
\text { agenda esportiva, } \\
\text { foto-legenda, } \\
\text { *infográfico }\end{array}$ & $\begin{array}{l}\text { Esporte*: notícia, } \\
\text { reportagem, placar, } \\
\text { agenda esportiva, } \\
\text { foto-legenda, } \\
\text { *infográfico }\end{array}$ & $\begin{array}{l}\text { Esporte }^{*} \text { : notícia, } \\
\text { reportagem, placar, } \\
\text { agenda esportiva, } \\
\text { foto-legenda, } \\
\text { *infográfico. }\end{array}$ \\
\hline Colunas & Colunas & Colunas & Colunas & Colunas \\
\hline Informe Folha: nota & Informe Folha: nota & Informe Folha: nota & Informe Folha: nota & Informe Folha: nota \\
\hline $\begin{array}{l}\text { Luiz Geraldo } \\
\text { Mazza: nota } \\
\text { comentada }\end{array}$ & $\begin{array}{l}\text { Luiz Geraldo } \\
\text { Mazza: nota } \\
\text { comentada }\end{array}$ & $\begin{array}{l}\text { Luiz Geraldo } \\
\text { Mazza: nota } \\
\text { comentada }\end{array}$ & $\begin{array}{l}\text { Luiz Geraldo } \\
\text { Mazza: nota } \\
\text { comentada }\end{array}$ & $\begin{array}{l}\text { Luiz Geraldo } \\
\text { Mazza: nota } \\
\text { comentada }\end{array}$ \\
\hline $\begin{array}{l}\text { Cláudio Humberto: } \\
\text { nota comentada }\end{array}$ & $\begin{array}{l}\text { Cláudio Humberto: } \\
\text { nota comentada }\end{array}$ & $\begin{array}{l}\text { Cláudio Humberto: } \\
\text { nota comentada }\end{array}$ & $\begin{array}{l}\text { Cláudio Humberto: } \\
\text { nota comentada }\end{array}$ & $\begin{array}{l}\text { Cláudio Humberto: } \\
\text { nota comentada }\end{array}$ \\
\hline $\begin{array}{l}\text { Dora Kramer: } \\
\text { ensaio }\end{array}$ & $\begin{array}{l}\text { Dora Kramer: } \\
\text { ensaio }\end{array}$ & & & \\
\hline
\end{tabular}

Esse quadro ilustra como se dá a divisão dos gêneros inventariados nas seções do Primeiro Caderno. Os gêneros foram inventariados, de maneira geral, no Primeiro Caderno, entretanto, há um "arranjo" e eles são divididos por seção, de acordo com a função comunicativa que desempenham. Isso pode ser comprovado pelas próprias seções do jornal, ou seja, na seção opinião, o principal objetivo é trazer opinião, crítica, argumentos aos leitores, assim, os gêneros que cumprem esse objetivo de comunicação são os gêneros com teor opinativo como a carta do leitor, artigo de opinião, etc. Dessa forma, cada seção veicula os gêneros que cumprem com o propósito comunicativo previsto: informar, entreter, analisar, 
etc. Por mais geral que seja a seção, como é o caso de Política, Geral e Mundo, os gêneros não sofrem variações, pois o principal objetivo dessas seções é noticiar, relatar, analisar, ou seja, prevalecem os gêneros com caráter mais informativo como a notícia e a reportagem. Assim também ocorre com as colunas em que aparecem os gêneros que exercem o propósito comunicativo do colunista. Portanto, o Primeiro Caderno, diferentemente do Folha 2, Folha Cidade, não é um caderno tão híbrido, ou seja, não veicula tantos gêneros de outras esferas sociais, mas prevalece com gêneros característicos da esfera jornalística.

\section{CONSIDERAÇÕES FINAIS}

A abordagem dada aos gêneros jornalísticos no ensino tem se tornado cada vez mais significativa. Dessa forma, o estudo desses gêneros faz-se necessário, uma vez que a sua classificação ainda não é clara para muitos educadores. Assim, espera-se que este estudo possa contribuir com outras pesquisas voltadas para a transposição didática dos gêneros jornalísticos, especialmente os veiculados no Primeiro Caderno do jornal Folha de Londrina.

\section{REFERÊNCIAS}

BARROS, Eliana Merlin Deganutti. Gestos de ensinar e de aprender gêneros textuais: a sequência didática como instrumento de mediação. 366f. Tese (Doutorado em Estudos da Linguagem) - Universidade Estadual de Londrina, Londrina, 2012.

BELTRÃO, Luiz. A imprensa informativa. São Paulo: Falco Masucci, 1969.

. Jornalismo interpretativo. Porto Alegre: Sulina/ARI, 1976.

Jornalismo opinativo. Porto Alegre: Sulina/ARI, 1980.

BONINI, Adair. Os gêneros do jornal: o que aponta a literatura da área de comunicação no Brasil? Linguagem em (Dis)curso, Tubarão, v. 4, n.1, p. 205-231, jul./dez. 2003.

As relações constitutivas entre o jornal e seus gêneros: relato das pesquisas do 'Projeto Gêneros do Jornal'. In: Sandro Braga; Maria Ester Wollstein Moritz; Mariléia Silva dos Reis; Fábio José Rauen. (Org.). Ciências da linguagem: avaliando o percurso, abrindo caminhos. Blumenau: Nova Letra, 2008, p. 21-45.

Atividade de linguagem, textos e discursos: por um interacionismo sóciodiscursivo. São Paulo: EDUC, 2003.

BRONCKART, Jean-Paul. Entrevista com Jean-Paul Bronckart. Revista Virtual de Estudos da Linguagem - REVEL. Ano 4, n. 6, março de 2006(a). Disponível em: 
$<$ http://paginas.terra.com.br/educacao/revel/edicoes/num_6/entrevista_bronckart.htm. Acesso em: 31 jul. 2006.

DOLZ, Joaquim; NOVERRAZ, Michlèle; SCHNEUWLY, Bernard. Sequências didáticas para o oral e a escrita: apresentação de um procedimento. In: SCHNEUWLY, Bernard; DOLZ, Joaquim (Org.). Gêneros orais e escritos na escola. Campinas: Mercado das Letras, 2004. p. 95-128.

FARIA, Maria Alice; ZANCHETTA JR, Juvenal. Para ler e fazer o jornal na sala de aula. 2. ed. $1^{\circ}$ reimp. São Paulo: Contexto, 2007.

FRANCESCHINI, Felipe. Notícia e reportagem: sutis diferenças. Comum, Rio de Janeiro, v.9, n.22, p. 144-155, jan./jun. 2004.

MACHADO, Anna Rachel; CRISTÓVÃO, Vera Lúcia Lopes. A construção de modelos didáticos de gêneros: aportes e questionamentos para o ensino de gêneros. Linguagem em (Dis)curso, Tubarão, v. 6, n. 3, p. 547-573, set./dez. 2006.

MARCUSCHI, Luiz Antônio. A questão do suporte dos gêneros textuais. Língua, linguística e literatura, João Pessoa, v. 1, n.1, p. 9-40, 2003.

MARCUSCHI, Luiz Antônio. Produção textual, análise de gêneros e compreensão. São Paulo: Parábola, 2008.

MELO, José Marques de. A opinião no jornalismo brasileiro. Petrópolis: Vozes, 1985.

MEDINA, Jorge Lellis Bomfim. Gêneros jornalísticos: repensando a questão. Symposium Ano 5, n. 1, jan./jun. 2001.

VYGOTSKY, Lev Semonovich. Pensamento e linguagem. 4. ed. São Paulo: Martins Fontes, 2008.

\section{AS AUTORAS}

Rithielle Aparecida Castellani é estudante do $3^{\circ}$ ano de Letras da Universidade Estadual do Norte do Paraná (UENP-Cornélio Procópio). É aluna de Iniciação Científica desde o $1^{\circ}$ ano da graduação. Bolsista da CAPES no período de agosto de 2013 a julho de 2014 e, da Fundação Araucária, de agosto de 2014 a julho de 2015. É voluntária do subprojeto PIBID-CAPES "Letramentos na escola: práticas de leitura e produção textual", coordenado pela Profa. Dra. Eliana Merlin Deganutti de Barros, cujo foco é a didatização dos gêneros do jornal. Desenvolve trabalhos na área da Linguística Aplicada, a partir do aporte teórico-metodológico do Interacionismo Sociodiscursivo.

E-mail: rithielle1995@hotmail.com

Eliana Merlin Deganutti de Barros é Doutora e Mestre em Estudos da Linguagem pela Universidade Estadual de Londrina (UEL). Professora adjunta da Universidade Estadual Norte do Paraná (UENP), atuando como docente na graduação em Letras, na Especialização em Ensino da Língua Portuguesa e no PROFLETRAS. Pesquisadora dos GP GETELIN (UENP), GEMFOR (UEL) e GETFOR (UFGD). Coordenadora de subprojeto PIBID 
"Letramentos na escola: práticas de leitura e produção textual". Atua na área de Linguística Aplicada, desenvolvendo pesquisas com: formação de professores, letramento, ensino/aprendizagem da Língua Portuguesa, gênero textual e transposição didática a partir do procedimento sequência didática.

E-mail: edeganutti@hotmail.com 